\title{
An Evaluation of Smart Clip Self-Ligating Bracket System: Comparison of Treatment Outcome and Patient Response between Self-ligating and Conventional Pre-adjusted Edgewise Appliance
}

\author{
Dr Virag Bhatia,' Dr Anmol S. Kalha,2 Dr Smruti Bhushan Nanda³ \\ 'Associate Professor, Dept of Orthodontics, Modern Dental College, Indore, India \\ ${ }^{2}$ Professor, Dept of Orthodontics, ITS Dental College, Noida, India \\ ${ }^{2}$ Associate Professor, Dept of Orthodontics, Institute of Dental Science, Bhubaneshwar, India
}

Correspondence: Dr. Virag Bhatia Email: viragbhatia@gmail.com

\section{ABSTRACT}

Introduction: A number of studies have been undertaken to evaluate the friction characteristics of self-ligating brackets, however there have been only few studies which have actually evaluated the clinical efficiency of these self-ligating brackets.

Objective: To evaluate the clinical efficiency of Smart Clip self-ligating bracket in terms of treatment time, number of appointments, $\mathrm{ABO}$ score, and patient perception by comparing it with a pre-adjusted edgewise appliance system (MBT).

Materials \& Method: A prospective in vivo study in which twelve patients were bonded with Smart Clip self-ligating appliance and twelve patients were bonded with conventional pre adjusted edgewise appliance (MBT). The record of number of visits was maintained for each visit. At the end of treatment all 24 patients were asked to fill a questionnaire consisting of 10 questions. Post-treatment OPG and study models of all cases were evaluated for ABO score.

Result: Average treatment time with Smart Clip self-ligating bracket was 4.5 months shorter than conventional pre-adjusted edgewise bracket. Mean number of appointments with Smart-Clip self-ligating brackets were 6.5 less than conventional pre-adjusted edgewise bracket. There was no significant difference in the quality of treatment with both groups having similar $A B O$ scores. Patient perception to treatment in both the groups was also similar, except that patients with Smart Clip appliance system experienced more pain during wire insertion. Smart Clip group patients had greater difficulty in maintaining oral hygiene.

Conclusion: Smart Clip bracket system is efficient in reducing the treatment time, but the quality of orthodontic treatment is similar to conventional pre-adjusted edgewise system. Patient perception for both the brackets is similar.

Key words: Smart Clip bracket system, MBT brackets, ABO score

\section{INTRODUCTION}

There have been many innovations and advancements in the field of orthodontics in the last three decades. All these advancements were made either to increase the treatment efficiency or to increase patient comfort.

A revolutionary change in the history of bracket system was the introduction of self-ligating brackets. ${ }^{1,2,3}$ Though a number of studies ${ }^{4-32}$ have been undertaken to evaluate the friction characteristics of self-ligating brackets, there have been only few studies which have actually evaluated the clinical efficiency of self-ligating brackets. This study was done to evaluate the clinical efficiency of Smart Clip self-ligating bracket in terms of treatment time, number of appointments, $A B O$ score, and patient perception by comparing it with a pre-adjusted edgewise appliance system (MBT).

\section{OBJECTIVE}

1. To compare Smart Clip self-ligating bracket to conventionally ligated pre-adjusted edgewise bracket and evaluate whether there are any difference in treatment time and number of appointments required to complete the treatment.

2. To evaluate the quality of treatment outcome by measuring post-treatment study models and radiographs using the grading criteria for certification as set by the American Board of Orthodontics.

3. To survey the sample using questionnaire about their perceptions of orthodontic treatment ranging from oral hygiene, discomfort and satisfaction of treatment. 


\section{MATERIALS AND METHOD}

This was a prospective in vivo study conducted at the Department of Orthodontics, College of Dental Sciences, Davangere, India. The patients included in the study were selected randomly from the OPD. Patients undergoing first premolar extractions were allotted randomly to both groups. Materials used for the study were treatment records of all 24 patients, post-treatment study models and OPG, ABO scale, viewer box. All 24 patients were bonded in the duration of four months. The records of number of visits were maintained on each visit of the patient. At the end of treatment all the 24 patients were asked to fill a questionnaire. Post-treatment OPG and study models of all cases were evaluated for $A B O$ score. After the completion of the treatment, patients were given oral instructions together with an explanation on how to complete the questionnaire. The questionnaire consisted of 10 questions. The question no. 1 to 6 evaluated a visual analogue scale, whereas question no. 7 to 10 were objective questions, in which the patient had to mark any one option. For groupwise comparisons unpaired t-test or Mann-Whitney tests were used wherever appropriate. Categorical data were analyzed by Fisher's exact test and p-value was kept at 0.05 for statistical significance.

\section{RESULT}

Average treatment time to complete treatment with Smart Clip self-ligating brackets was 14 months whereas that with MBT appliance system was 18.5 months (Table I, Graph 1. The mean number of appointments required to complete

Table 1: Descriptive statistics for differences in treatment time, number of appointments and ABO score based on bracket types

\begin{tabular}{|l|c|c|c|c|c|c|c|c|c|}
\hline \multirow{2}{*}{\multicolumn{1}{|c}{ Measurement }} & \multicolumn{3}{|c|}{ Smart Clip } & \multicolumn{3}{c|}{ MBT } & \multicolumn{3}{c|}{ Smart Clip vs. MBT } \\
\cline { 2 - 12 } & Mean \pm SD & Median & Range & Mean \pm SD & Median & Range & $\begin{array}{c}\text { Mean } \\
\text { difference }\end{array}$ & t-value & p-value \\
\hline Time taken (months) & $14.0 \pm 2.6$ & 13.5 & $11-18$ & $18.5 \pm 2.3$ & 18 & $16-22$ & 4.5 & 3.20 & $0.011^{*}$ \\
\hline Appointments (number) & $14.7 \pm 2.2$ & 14.5 & $12-18$ & $21.2 \pm 2.3$ & 21.5 & $18-24$ & 6.5 & 5.03 & $0.001^{*}$ \\
\hline ABO score (deductions) & $17.2 \pm 1.5$ & 17.5 & $15-19$ & $19.5 \pm 5.3$ & 17.5 & $15-29$ & 2.3 & 1.04 & 0.32 (NS) \\
\hline
\end{tabular}

t: unpaired t-test, *Significant, NS: Not significant

Table 2: Descriptive statistics for differences in patient response based on bracket type

\begin{tabular}{|c|c|c|c|c|c|c|c|}
\hline \multirow{2}{*}{ Question No. } & \multicolumn{3}{|c|}{ Smart Clip } & \multicolumn{3}{|c|}{ MBT } & \multirow[b]{2}{*}{$p$-value } \\
\hline & Mean \pm SD & Median & Range & Mean \pm SD & Median & Range & \\
\hline Q1 & $4.8 \pm 1.2$ & 5.0 & $3-6$ & $5.5 \pm 3.2$ & 6 & $2-9$ & $0.87, \mathrm{NS}$ \\
\hline Q2 & $2.2 \pm 0.8$ & 2.0 & $1-3$ & $1.2 \pm 0.8$ & 1 & $0-2$ & $0.07, \mathrm{NS}$ \\
\hline Q3 & $7.2 \pm 1.7$ & 7.0 & $5-9$ & $2.5 \pm 2.7$ & 1.5 & $1-8$ & $<0.05, \mathrm{~S}$ \\
\hline Q4 & $6.0 \pm 2.4$ & 7.0 & $2-8$ & $4.7 \pm 2.8$ & 4 & $1-8$ & $0.56, \mathrm{NS}$ \\
\hline Q5 & $4.5 \pm 1.4$ & 4 & $3-7$ & $1.7 \pm 0.5$ & 2 & $1-2$ & $<0.01, \mathrm{~s}$ \\
\hline Q6 & $7.8 \pm 1.6$ & 8.5 & $5-9$ & $8.3 \pm 0.5$ & 8 & $8-9$ & $0.93, N S$ \\
\hline
\end{tabular}

* Mann-Whitney test

Table 3: Descriptive statistics for differences in patient responses bases in bracket types

\begin{tabular}{|c|c|c|c|c|}
\hline \multirow{2}{*}{ Question No. } & \multirow{2}{*}{ Options } & Smart Clip & MBT & \multirow{2}{*}{ Smart Clip vs. MBT* } \\
\hline & & Number (\%) & Number (\%) & \\
\hline \multirow{2}{*}{ Q7 } & Yes & $12(100)$ & $12(100)$ & \multirow{2}{*}{$p=1.00, N S$} \\
\hline & No & 0 & 0 & \\
\hline \multirow{2}{*}{ Q8 } & Right amount & $12(100)$ & $6(50)$ & \multirow{2}{*}{$p=0.07, N S$} \\
\hline & Too little & 0 & $6(50)$ & \\
\hline \multirow{2}{*}{ Q9 } & Too short & $4(33.3)$ & $6(50)$ & \multirow{2}{*}{$p=0.59, \mathrm{NS}$} \\
\hline & Too long & $8(66.7)$ & $6(50)$ & \\
\hline \multirow{2}{*}{ Q10 } & Longer than expected & $4(33.3)$ & $8(66.7)$ & \multirow{2}{*}{$p=0.29, N S$} \\
\hline & Shorter than expected & $8(66.7)$ & $4(33.3)$ & \\
\hline
\end{tabular}

\footnotetext{
* Fisher's exact test
} 
treatment with Smart Clip self-ligating brackets was 14.7, whereas that with MBT appliance system was 21.2 (Table I, Graph 2). The mean $A B O$ score for Smart Clip self-ligating brackets was 17.2 whereas that of MBT appliance system was 19.5 (Table I). Furthermore analysis of questionnaire revealed that both the groups were satisfied with the outcome of treatment, however Smart Clip group patient experienced greater pain during archwire insertion and removal (Table 2, 3).

\section{DISCUSSION}

Average treatment time with Smart Clip self-ligating brackets was 14 months whereas that with MBT appliance system was 18.5 months. The mean difference in treatment time between the two groups was 4.5 months, which showed that treatment time was reduced by 4.5 months with Smart Clip self-ligating brackets. A similar study ${ }^{27}$ comparing treatment time between Damon self-ligating brackets and conventional pre-adjusted edgewise brackets showed an average reduction in treatment time of 6.46 months with Damon self-ligating brackets. Another study ${ }^{24}$ reported a mean reduction in treatment time of 2.8 months with Damon selfligating bracket as compared to conventional pre-adjusted edgewise bracket. In another study ${ }^{34}$ the author compared the effectiveness of Smart Clip brackets and conventional twin brackets for initial alignment of lower arch. The author did not find any statistical significant difference in irregularity between the two groups. The authors concluded that Smart Clip was not effective at reducing irregularity during the initial stage of treatment than a conventional twin bracket. Similar study 35 was done to compare the effectiveness of Damon 2 brackets and conventional twin brackets during initial alignment. The study demonstrated that the Damon 2 bracket had $0.2 \mathrm{~mm}$ greater irregularity, so clinically it did not perform better than the conventional twin bracket.

The mean number of appointments required to complete the treatment with Smart Clip self-ligating brackets in this study was 14.7, whereas that with MBT appliance system was 21.2. This showed that patients in Smart Clip appliance group required statistically less appointments to get their treatment completed $(p=0.001)$. Similar study ${ }^{27}$ was done to compare number of appointments required to complete treatment with Damon self-ligating bracket and conventional pre-adjusted edgewise bracket. They reported that Damon brackets required an average of 6.81 less appointments to complete treatment as compared to conventional pre-adjusted edgewise brackets. In another study ${ }^{24}$ Damon self-ligating brackets required on an average 4.6 fewer appointments than the conventional edgewise brackets.

In this study, the mean $A B O$ score deduction for Smart Clip self-ligating brackets was 17.2, whereas that of MBT appliance was 19.5. The mean difference in $A B O$ score of two groups was 2.3, which was not statistically significant $(p=0.32)$. This means that finish in both the groups was similar. In another study ${ }^{27} \mathrm{ABO}$ score was compared between Damon self-ligating brackets and conventional pre-adjusted edgewise brackets. The mean difference between the two groups was 5.31 and was statistically significant. The questionnaire results show that both Smart Clip and MBT group patients had similar perceptions about their treatment. The only significant difference was for question 3 and 5 , where the patients in Smart Clip group felt severe pain during the placement of the wire compared to MBT group. This may be due to the presence of NiTi clips in Smart Clip which offers resistance to the placement of the wire. Also the patient in the Smart Clip group had a greater difficulty in maintaining oral hygiene compared to MBT group; which may be due to the increased size of Smart Clip brackets compared to MBT brackets.

The reason for reduced treatment time with Smart Clip self-ligating bracket can be due to the passive ligation of the system ${ }^{42}$. The arch wire is "passively" held in the bracket by means of the programmed nickel-titanium clip. Studies have been undertaken to determine the benefits of selfligating brackets. Excellent research has been accomplished by Thorstenson and Kusy. ${ }^{28}$ Their findings indicate that not only do self-ligating brackets have a performance edge over mini-twin brackets during leveling and alignment, but additionally retain an advantage during sliding mechanics in an experimental basis. Yeh et $\mathrm{a}^{36}$ in the in vitro study found that Smart Clip had a greater critical angle compared to Damon brackets and Synergy brackets, when coupled with a $0.016 \times 0.022$ " NiTi archwire. Though Smart Clip had a greater critical angle they found no difference in all types of brackets in the binding conditions of second order intrusions. They also found that because the Smart Clip brackets had the greatest clearance of the tested brackets, the clip design resulted in the greatest bracket width (smallest interbracket distance), which decreased archwire flexibility and impeded the frictional resistance values.

Lastly, increased pain experienced by patients during wire insertion when using the Smart Clip appliance demonstrates the need for further research involving the engagement forces of the Smart Clip bracket.

\section{CONCLUSION}

It can be concluded that though Smart Clip bracket system are efficient in reducing the treatment time. The quality of orthodontic treatment is similar to conventional pre-adjusted edgewise system. Patient perceptions for both the brackets are similar. 


\section{REFERENCES}

1. Stolzenberg J. The Russell attachment and its improved advantages. Int. J. Orthod. Dent. Child 1935; $21: 837-840$.

2. Stolzenberg J. The efficiency of the Russell attachment. J. Orthod. Oral Surg 1946; 32: 572-582.

3. Hanson GH. The SPEED System: A report on the development of new edgewise appliance. Am. J. Orthod 1980 ; $78: 243-265$.

4. Drescher D, Bourauel C, Schumacher H. A. Frictional forces between brackets and arch wire. Am. J. Orthod 1989; 96 : $397-404$.

5. Rolf Maijer, Dennis C. Smith. Time savings with self-ligating brackets. J Clin Orthod 1990; 24:29-31.

6. Jeffrey L Berger, Windsor. The influence of SPEED bracket's self-ligating design on force levels in tooth movement. Am J Orthod Dentofac Orthop. 1990; 97: 219-228.

7. James R. Brednar, and Gary W. Gruendeman. Am J Orthod Dentofac Orthop 1993; 104: 254-261

8. Shivapuja PK, Jeff Berger. A comparative study of conventional ligation and self-ligation bracket systems Am J Orthod Dentofac Orthop 1994 ; 106: 472-480.

9. Sims AP, Waters N, and Birnie D. A comparison of the forces required to produce tooth movement ex vivo through three types of preadjusted brackets when subjected to determined tip or torque values. $\mathrm{Br} J$ Orthod $1994 ; 21: 367-373$.

10. Berger JL. The SPEED Appliance: A 14-year update on this unique self-ligating orthodontic mechanisum. Am J Orthod Dentofacial Orthop $1994 ; 105: 217-23$

11. Harradine NWT, Birnie DJ. The clinical use of Activa self-ligating brackets. Am J Orthod Dentofacial Orthop 1996; 109:319-28.

12. Taylor NG, Ison K. Frictional resistance between orthodontic brackets and arch wires in the buccal segments. Angle Orthod 1996; 66: 215-222.

13. Voudouris JC. Interactive edgewise mechanisms: form and function comparison with conventional edgewise brackets. Am J Orthod Dentofacial Orthop 1997; 111: 119-40.

14. Readward GE, Jones SP, Davies EH. A comparison of self-ligating and conventional orthodontic bracket systems. Br J Orthod 1997; 24:309-317

15. Voudouris JC. Seven clinical principles of Interactive twin mechanisms. J Clin Orthod 1997;31:55-65

16. Kapur R, Sinha PK, Nanda RS. Frictional resistance of Damon SL bracket. J Clin Orthod 1998; 32:485-489.

17. Pizzoni L, Ravnholt G, Melson B. Frictional forces related to self-ligating brackets. Eur J Orthod 1998; 20: $283-291$.

18. Damon DH. The Damon low friction bracket: A biologically compatible straight-wire system. J Clin Orthod 1998; 32:670-680.

19. Heiser W. A new orthodontic philosophy. J Clin Orthod 1998; 35: 44-53.

20. Thomas S, Sherriff M, Birnie D. A. comparative in vitro study of the frictional characteristics of two types of self-ligating brackets and two types of pre-adjusted edgewise brackets tied with elastomeric ligature. Eur J Orthod 1998;20:589-596.

21. Loftus BP, Artun J, Nicholls JI, Alonzo TA, Stoner JA. Evaluation of friction during sliding tooth movement in various bracket- arch wire combinations. Am J Orthod Dentofacial Orthop 1999;1 16:336-345.

22. Hanson GH. The SPEED bracket auxiliary slot. J Clin Orthod 1999; 33:318-321.

23. Berger J. Self-Ligation in the year 2000. J Clin Orthod Feb 2000; 34:74-81.

24. Harradine NWT. Self-ligating brackets and treatment efficiency. Clin. Orthod. Res. 2001; 4: $220-227$.

25. Berger J, Byloff FK. The clinical efficiency of self-ligated brackets. J Clin Orthod 2001; 35: 304-310.

26. Thorstenson GA, Kusy RP. Resistance to sliding of self-ligating brackets verses conventional stainless steel twin brackets with second order angulations in the dry and wet (saliva) states. Am J Orthod Dentofacial Orthop 2001; 120:361-370.

27. Eberting JJ, Straja SR, Tuncay OC. Treatment time, outcome, and patient satisfaction comparisons of Damon and conventional brackets. Clin. Orthod. Res. 2001; 4:228-234.

28. Thorstenson A, Kusy RP. Comparison of resistance to sliding between different self-ligating brackets with second order angulations in the dry and wet saliva states. Am J Orthod Dentofacial Orthop 2002; 121:472-482.

29. Hain M, Dhopatkar A, Rock P. The effect of ligation method on friction in sliding mechanics. Am J Orthod Dentofacial Orthop 2003; 123: 416-422.

30. Mah E, Bagby M, Ngan P, Durkee M. Investigation of frictional resistance on orthodontic brackets when subjected to variable moments. Am J Orthod Dentofacial Othop 2003;123: 90-100

31. Redlich M, Mayer Y, Harari D, Lewinstein I. In vitro study of frictional forces during sliding mechanics of "reduced friction" brackets. Am J Orthod .Dentofacial Orthop 2003; 124(1):69-73.

32. Cacciafesta $V$, Sfondrini MF, Riccardi A, Scribante A, Klersy C, Auricchio F. Evaluation of friction of stainless steel and esthetic self-ligating brackets in various bracket-archwire combinations. Am J Orthod Dentofacial Orthop 2003; 124:395-402.

33. Harradine NWT. Self-ligating brackets: where are we now? JO 2003; 30: 262-273.

34. Miles PG. SmartClip versus conventional twin brackets for initial alignment: is there a difference? Aust Orthod J 2005; 21 : $123-127$.

35. Miles PG, Weyant RJ, Rustveld. A Clinical Trial of Damon $2^{\text {TM }}$ Vs Conventional Twin Brackets during Initial Alignment. AO 2006 ; 76 : 480-485.

36. Yeh CL, Kusnoto B, Viana G, Evans CA, Drummond JL. In- vitro evaluation of frictional resistance between brackets with passive- ligation designs. Am J Orthod Dentofacial Orthop 2007;131:704.e1 1-704.e22. 